\title{
CD4: a vital player in the teleost fish immune system
}

\author{
Hassan Ashfaq, Hatem Soliman, Mona Saleh and Mansour El-Matbouli *
}

\begin{abstract}
CD4 is a nonpolymorphic transmembrane glycoprotein molecule that is expressed on the surface of T-helper cells and plays an essential role in the immune response. It functions as a coreceptor with the T-cell receptor by binding to major histocompatibility complex class II on the surface of dendritic cells that present antigens. CD4 ${ }^{+} \mathrm{T}$ cells hold a key position in coordinating the immune system through production of several cytokines after activation and differentiation. The CD4 ${ }^{+}$T helper subtypes (T-helper 1, T-helper 2, T-helper 17, T-helper 9, and regulatory-T cells) perform different immune functions subsequent to their differentiation from the naive T cells. Different types of CD4 ${ }^{+} T$ cells require different cytokines such as drivers and effectors, as well as master transcription factors for their activation. Fish cells that express CD4-related genes are activated in the presence of a pathogen and release cytokines against the pathogen. This review highlights the types of $\mathrm{CD}^{+} \mathrm{T}$ cells in fish and describes their direct role in cell-mediated and humoral immunity for protection against the intracellular bacterial as well as viral infections in fish.
\end{abstract}

\section{Table of Contents}

1 Introduction

2 Functions of $\mathrm{CD} 4^{+} \mathrm{T}$ cells in fish

3 Molecular characterization of CD4 in fish

4 Antibodies used to study the expression of $\mathrm{CD} 4^{+} \mathrm{T}$ cells in fish

$5 \mathrm{CD} 4{ }^{+} \mathrm{T}$ cell subtypes

6 Potential factors for differentiation of $\mathrm{CD} 4^{+} \mathrm{T}$ cell subtypes in fish

$6.1 \mathrm{~T}_{\mathbf{h}} 1$ cell differentiation

6.2 $\mathrm{CD}^{+} \mathrm{T}_{\mathbf{h}} 2$ cell differentiation

$6.3 \mathrm{CD} 4{ }^{+} \mathrm{T}_{\mathbf{h}} 17$ differentiation

6.4 $\mathrm{CD}^{+}{ }^{+}$regulatory $\mathrm{T}$ cell differentiation

$7 \mathrm{CD} 4^{+} \mathrm{T}$ cell response against pathogens

8 Conclusions

References

\section{Introduction}

The fish immune system is categorized into innate and adaptive immunity. Adaptive immunity is the subsequent defense barrier of the immune system that pathogens encounter if they overcome the physical barrier and the other elements of innate immunity [1]. The adaptive immune system identifies pathogens with the help of molecules that are generated via somatic mechanisms through the generation of B- and T-lymphocytes [2]. In fish, cell-mediated immune response is governed by different types of leukocytes including T-lymphocytes, which comprise cytotoxic T-lymphocytes (CTLs) and $\mathrm{T}$ helper cells $\left(\mathrm{T}_{\mathrm{h}}\right)$ [3]. These cells express different cell markers which allow distinguishing among them [4]. The initiation of a response to an antigen is always presided over by a specific receptor known as the $\mathrm{T}$ cell receptor (TCR), which demarcates the T-cells from the other lymphocytes [5]. CD4 is a transmembrane glycoprotein expressed on the surface of $\mathrm{T}_{\mathrm{h}}$ cells and plays an essential role in the immune response. T-helper cells that express CD4 $\left(C D 4^{+} \mathrm{T}_{\mathrm{h}}\right.$ cells) coordinate the immune response by acting either as effector cells or as memory cells [6]. CD $4^{+} \mathrm{T}_{\mathrm{h}}$ cells usually perform the "helper" cell functions [7]. In fish, $\mathrm{CD} 4^{+} \mathrm{T}$ cells' function is thought to be comparable to 
that of mammals due to the presence of TCRs, CD4like genes with the same number of domains (D1-D4) and an important structural factor such as Lck Motif [8]. The characterizations of $\mathrm{CD}^{+}$cell populations and functions have been defined due to the availability of suitable markers for T-lymphocytes in fish. CD4 ${ }^{+}$ $\mathrm{T}_{h}$ cells are essential for triggering and maintaining both natural and vaccine-induced immunity [9]. This review discusses the importance of $\mathrm{CD}^{+} \mathrm{T}$ helper cells and their role in adaptive immunity, focusing on their types, characterization, expression, differentiation pattern, operational mechanism, and signaling to the other components of the immune system in fish.

\section{Functions of $\mathrm{CD}^{+} \mathrm{T}$ cells in fish}

Initiation of $\mathrm{T}$-cell response requires complex cellular interaction involving both polymorphic and non-polymorphic regions of TCR, mediated by MHC class I and II molecules and enhanced by their coalition with $\mathrm{T}$ cell co-receptors i.e., CD4 and CD8 [10]. Surprisingly, the $\mathrm{MHC}$ class II and CD4 related genes were observed to be missing in only one fish type, the Atlantic cod, possibly because of a genetic modification. As far as the functional organization of the fish thymus is concerned, it is perhaps analogous to the thymus in mammals; this is inferred considering the expression sites of the recombination activating gene (RAG) [11]. CD4 ${ }^{+} \mathrm{T}$ cells, particularly in fish, have been investigated in several studies. These $\mathrm{CD}^{+}{ }^{+} \mathrm{T}$ cells accomplish several functions in fish (Figure 1), such as stimulating macrophages to boost microbicidal activity and B-cells to produce antibodies, as well as enhancing cell-mediated immunity [12]. These cells also support the employment of neutrophils, eosinophils, and basophils to the inflammation site, the antigen-specific proliferation, maneuvering the immune response, and the regulation/suppression of the immune responses [13], thereby establishing a base for a superior overall immune response. Adaptive immune response relies on the stimulation by T-helper cells, which express several cell-surface markers, among which CD4 is the most effective marker to delineate the T-helper subsets [14]. CD4 is not expressed by the other adaptive immune cells such as CLT, however, it is also expressed by a few subsets of dendritic cells and macrophages. CD4 was reported to be connected through an interface with an antigen (e.g., bacteria) of extracellular origin in ginbuna carp [15]. In viral infection, a skewed immune response triggered by $\mathrm{CD}^{+}{ }^{+}$cells via upregulation of IL-12 cytokine through stimulation by CTL was observed in the common carp [4]. Similarly, in extracellular parasitic infection, higher expression of cytokine genes related to a particular $\mathrm{CD} 4^{+}$ cell was observed in fugu [13].

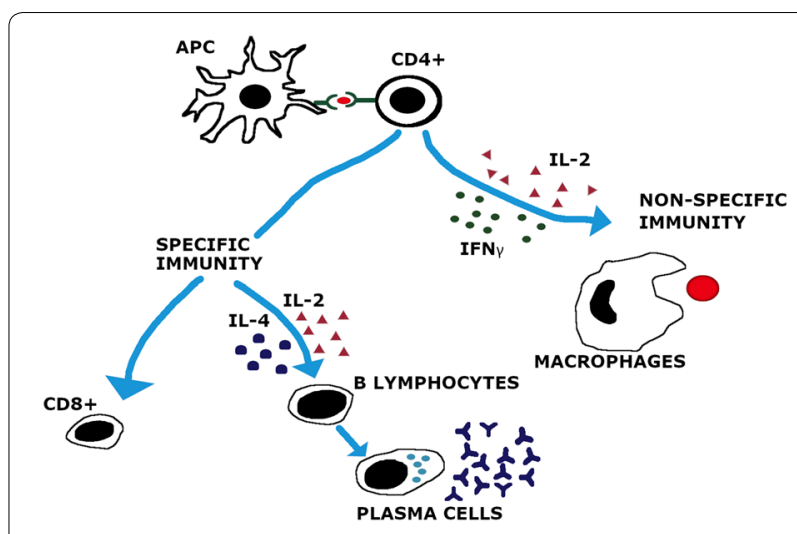

Figure 1 CD4 cells orchestrating immune response. Recruitment of CD8, B lymphocytes and Macrophages by CD4 cells and production of different interleukins and interferon's to carry out desired protection against various organisms, equally important for specific and non-specific immunity. Assembly of inflammatory cytokines in fish with infection is triggered, subject to leukocyte mobilization. Activated T-helper cells with CD4 co-receptor, produces $\mathrm{IL}-2$ and IFN- $\gamma$ to encourage macrophage activation for a general non-specific immune response. Likewise, IL-2 and IL-4 elicit response of B lymphocytes for specific immunity.

\section{Molecular characterization of CD4 in fish}

Mammalian CD4 belongs to the immunoglobulin superfamily and contains four Ig-like domains (D1-D4) and important cytoplasmic tail linked with p56lck or tyrosine kinase protein [16]. Two of the CD4 Ig-like domains are constant type-C (D2 and D4) and the other two are variable type-V (D1 and D3) [16]. Generally, teleost fish contain two CD4 genes; CD4-1 contains four Iglike domains, and CD4-2, contains two or three Ig-like domains. The p56lck motif in their cytoplasmic domain is responsible for intracellular signaling, resulting in a series of phosphorylation cascades, defining helper activity of the $\mathrm{T}$ cell, after interaction with an antigen [17]. These basic components (domains and cytoplasmic motifs) are important for primary processing and activation of $\mathrm{T}$ helper cells in rainbow trout after interaction with antigen as in mammals [8]. It has been established that immunoreceptor tyrosine-based activation motif (ITAM) acts as a bridge between TCR and internal cellular machinery [17].

Most fish species contain two types of CD4-like molecules, CD4-1 and CD4L-2 (or CD4REL) [8]. In rainbow trout, although the four Ig-like domains are comparable to those in the mammalian CD4 glycoprotein, the first domain lacks the cysteine (Cys) residue encoded by 12 exons [8] instead of 10 in humans [16] and birds [18]. The non-polymorphic region of MHC class II interacts with human CD4 mainly through strands of the D1 domain via amino acids [19]. Likewise, a similar D1 domain structure and only one Cys residue, instead of two in mammals and 
birds, were reported in fugu and many other fish species [20]. Additionally, the MHC II region binding to trout CD4 were found to be conserved between fish and mammals [21]. The role of the Lck motif has been very well studied in mammals, and its presence in fish may be suggestive of a similar role [20]. The dileucine motif in the cytoplasm, which is also important for the activation of T-cells was, however, found to be absent in both trout and fugu CD4 sequences, suggesting a slight variation in activity [8]. Table 1 gives a summary of the information regarding the characterization of $\mathrm{CD} 4$ in particular fish species (Table 1).

Two CD4 homologs have been documented in rainbow trout (Oncorhynchus mykiss), one (tCD4) with the standard four Ig-like domains, and the other (tCD4REL) with only two domains [8]. The rainbow trout CD4, tCD4, has a CXC chemokine receptor motif in its cytoplasmic domain which is involved in lymphocyte-specific protein tyrosine kinase (Lck) binding. A function similar to that in mammals has been suggested [8]. It is also reported that tCD4REL has the CXC motif serving as a binding site for p56LCK, suggesting the same function as CD4-1 in other fish species. The tCD4 encodes an open reading frame (ORF) of 489 amino acids, while tCD4REL encodes an ORF of 325 amino acids, sharing 90\% nucleotide identity with each other. The sequence alignment of tCD4REL with CD4 sequences from other species showed great similarity with regards to D1 and D2 domains, suggesting the same phenomenon of interaction with the MHC class II protein. Both tCD4 and tCD4REL have sites for glycosylation ( $\mathrm{N}$ and $\mathrm{O}$ types), similar to other species.
The N-terminus of fish Lck encompasses a CXXC motif and numerous other hydrophobic residues at the same position as in the mammalian Lck, indicating the interaction between CD4L-2 and Lck in fish. Like any other fish species, conserved Cys in the F strand of the D1 domain was identified but the Cys residue in the B strand of D1 (conserved in mammals) was absent for the disulphide bond in the rainbow trout CD4 sequence [8].

Fugu (Takifugu rubripes) CD4 gene encodes an ORF of 463 amino acids and contains four Ig-like domains (D1D4), a cytoplasmic domain, and a transmembrane region [22]. It contains four N-linked glycosylation sites in the D4 domain. In mammals, the disulfide bond in D1 and D2 is essential for binding with the MHC class II molecule; this bond is absent in the first two domains of fugu. However, a distinct type of disulfide bond at D3 is suggestive of a mechanism of interaction different than that in mammals. However, the tyrosine kinase motif p56lck (lck motif) present in the cytoplasmic domain, which is involved in T-cell maturation and signaling, is perceived to be conserved. A second CD4-like gene (CD4L-2), orthologue to the trout (CD4L-2) gene, with two Ig-like domains both (VC) type and similar cytoplasmic tail (Y-C-Q-C) motif for Lck binding was identified [23].

In Atlantic salmon (Salmo Salar) three CD4 genes were reported; CD4-1, CD4-2a, and CD4-2b [20]. A comparison of these genes with the documented teleost CD4 molecules affirmed the conserved cysteine sequences along with four extracellular Ig-like domains in CD4-1, two extracellular Ig-like domains in both CD4-2a and CD4$2 \mathrm{~b}$, and a cytoplasmic domain with Lck motif-binding

Table 1 CD4 features in fish.

\begin{tabular}{|c|c|c|c|c|c|c|}
\hline Species & $\begin{array}{l}\text { Number } \\
\text { of CD4+homologs }\end{array}$ & Types & (IG)-like domains & ORF & Gene accession number & References \\
\hline Rainbow trout & 2 & $\begin{array}{l}\text { tCD4 } \\
\text { CD4REL } \\
\text { CD4L2a 1,2 } \\
\text { CD4L-2b }\end{array}$ & $\begin{array}{l}\text { Four } \\
\text { Two }\end{array}$ & $\begin{array}{l}489 \\
334 \\
279.293 \\
315\end{array}$ & $\begin{array}{l}\text { AY973030 } \\
\text { AY973031 } \\
\text { AY899931,33 } \\
\text { AY899932 }\end{array}$ & $\begin{array}{l}{[8]} \\
{[23]}\end{array}$ \\
\hline Atlantic salmon & 3 & $\begin{array}{l}\text { CD4-1 } \\
\text { CD4-2a, CD4-2b }\end{array}$ & $\begin{array}{l}\text { Four } \\
\text { Two }\end{array}$ & $\begin{array}{l}490 \\
311.315\end{array}$ & $\begin{array}{l}\text { EU585750 } \\
\text { EU585752 } \\
\text { EU585751 }\end{array}$ & {$[20]$} \\
\hline Catfish & 2 & $\begin{array}{l}\text { IpCD4L-1 } \\
\text { IpCD4L-2 }\end{array}$ & $\begin{array}{l}\text { Four } \\
\text { Three }\end{array}$ & $\begin{array}{l}471 \\
412\end{array}$ & $\begin{array}{l}\text { DQ435301 } \\
\text { DQ435302 }\end{array}$ & {$[24]$} \\
\hline Common carp & 1 & CD4L & Four & 458 & DQ400124 & {$[27]$} \\
\hline Sea bass & 1 & CD4 & Four & 480 & AM849811 & {$[25]$} \\
\hline Fugu & 2 & $\begin{array}{l}\text { CD4L-1 } \\
\text { CD4L-2 }\end{array}$ & $\begin{array}{l}\text { Four } \\
\text { Two }\end{array}$ & 463 & $\begin{array}{l}\text { AB16405 } \\
\text { AB164055 }\end{array}$ & {$[22]$} \\
\hline Ginbuna carp & 2 & $\begin{array}{l}\text { CD4L-1a } \\
\text { CD4L-1b }\end{array}$ & $\begin{array}{l}\text { Four } \\
\text { Four }\end{array}$ & $\begin{array}{l}464 \\
263\end{array}$ & $\begin{array}{l}\text { AB331216 } \\
\text { AB331217 }\end{array}$ & {$[26]$} \\
\hline Atlantic halibut & 2 & $\begin{array}{l}\text { CD4-1 } \\
\text { CD4-2 }\end{array}$ & $\begin{array}{l}\text { Four } \\
\text { Two }\end{array}$ & $\begin{array}{l}462 \\
308\end{array}$ & $\begin{array}{l}\text { FJ185042 } \\
\text { GU985449 }\end{array}$ & $\begin{array}{l}{[28]} \\
{[29]}\end{array}$ \\
\hline Japanese Flounder & 2 & $\begin{array}{l}\text { jfCD4-1 } \\
\text { jfCD4-2 }\end{array}$ & $\begin{array}{l}\text { Four } \\
\text { Two }\end{array}$ & $\begin{array}{l}464 \\
302\end{array}$ & $\begin{array}{l}A B 643634 \\
A B 716324\end{array}$ & {$[3]$} \\
\hline
\end{tabular}


sites in all three homologs. The sequences in CD4-2 do not contain motifs for glycosylation, particularly of the $\mathrm{N}$-linked nature; nevertheless they contain numerous motifs for O-linked glycosylation indicating a different structure with the same function as in mammals.

Two CD4-like molecules, CD4L-1 and CD4L-2, are present in channel catfish (Ictalurus punctatus), sharing $19 \%$ amino acid identity with each other [24]. Similarly to mammals, the CD4L-1 gene encodes a protein containing four extracellular Ig-like domains and exhibits similar gene organization, while the CD4L-2 gene encodes a protein containing just three Ig-like domains and exhibits a genetic organization different than that in mammals. Both CD4L-1 and CD4L-2 contain a cytoplasmic motif with p56Lck-binding sites and four N-linked glycosylation sites. It was reported that the catfish $\mathrm{CD} 4$ gene sequence is diverse to the other fish $\mathrm{CD} 4$ sequences since it contains only three Ig-like domains and CD4L-2 has only $20-24 \%$ amino acid similarity with the CD4L of other fish species. Exon-intron arrangement in CD4L-1 appears to be similar to that of the mammalian and avian counterparts, while the CD4L-2 gene arrangement is completely different.

In sea bass (Dicentrarchus labrax), four Ig-like domains (D1-D4) are present, however, the number of Cys residues is different among all the domains, i.e., D1 contains one Cys residue (Cys114), while two Cys residues are present in D2 (Cys193 and Cys156), D3 (Cys233 and Cys316), and D4 (Cys355 and Cys404) [25]. Sea bass CD4 encodes 480 amino acids and contains the typical four Ig-like domains with cytoplasmic CXC Motif similar to mammals. It exhibits $40 \%, 30 \%$ and $33 \%$ of amino acid identity in rainbow trout, carp, and catfish, respectively and $23 \%$ with humans.

The CD4 homologs of ginbuna crucian carp (Carassius auratus langsdorfi) are of two types, namely CD4L1a and CD4L-1b, sharing 95\% identity with each other in terms of amino acid profile [26]. It was reported that both CD4L-1a and CD4L-1b contained four Ig-like domains (D1-D4), a cytoplasmic domain, and a transmembrane domain, similar to the CD4 from the other species. Phylogenetic investigation specified greater closeness of ginbuna crucian carp CD4 to the teleost CD4L-1, compared to teleost CD4L-2.

A single CD4 homolog, CD4L, was identified in common carp (Cyprinus carpio L) [26]. It contains four extracellular Ig-like domains, a transmembrane region, a cytoplasmic tail, a conserved tyrosine kinase motif p56lck and 21 phosphorylation sites. CD4L does not have a Cys residue for a disulphide bond, similar to fugu CD4, rainbow trout CD4L-1, channel catfish IpCD4L-1, and the D1domain in carp [26].

The Atlantic halibut (Hippoglossus hippoglossus) CD4-1 was reported to contain four Ig-like domains (D1-D4) [two V-types and two C-type] that were extracellular in nature and structurally analogous to the other documented CD4 in fish and mammals [28]. It contain three O-linked glycosylation sites at D3, three N-linked glycosylation sites similar to the conserved ones in almost all fish species excluding the zebrafish, and a CXC motif comparable to that in the other teleosts and mammals. A second halibut CD4-2 molecule was reported, which contained two Ig-like domains with three O-type glycosylation sites [29].

In Japanese flounder (Paralichthys olivaceus), two CD4 homolog were identified; jfCD4-1 and jfCD4-2 [3]. The first gene (jfCD4-1) encodes an ORF of 464 amino acids. It contains classical four Ig-like domains and an Lck binding motif in the cytoplasmic domain. Cysteine is absent in the first domain of the jfCD4-1 as in the other known CD4 from teleosts. It contains four N-linked glycosylation sites. However, jfCD4-2 encodes an ORF of 302 amino acids and contains two Ig-like domains with a conserved CXC Lck binding motif.

\section{Antibodies used to study the expression of $\mathrm{CD4}^{+}$ $T$ cells in fish}

Monoclonal antibodies (mAbs) against trout CD4-1 and CD4-2 were generated and validated to study the surface expression of CD4-1 and CD4-2 molecules in trout leukocytes [30]. Similarly, mAbs against teleost CD4 were produced in clonal ginbuna crucian carp (Carassius auratus langsdorfii) to investigate the functions of CD4 positive T cells [31]. Accordingly, it was suggested that the presence of CD4-positive $\mathrm{T}$ cells in the ginbuna crucian carp is the equivalent of the helper T-lymphocyte in mammals. Additionally, mAbs directed against thymocytes of rohu, (Labeo rohita) was developed and characterized [32]. This mAbs emerged to be a suitable marker for T-lymphocytes and could be a valuable tool in studying the immune response and ontogeny of the rohu immune system.

Furthermore, a polyclonal antibody against zebrafish (Danio rerio) CD4 (zfCD4-1) was developed and used to investigate whether $\mathrm{CD} 4-1^{+}$lymphocytes can express typical $\mathrm{T}_{h}$ cytokines following antigen specific stimulation [33]. The results of this endeavour revealed that $\mathrm{zfCD} 4-1^{+}$lymphocytes induce the expression of cytokines and master transcription factors relevant to $\mathrm{T}_{\mathrm{h} 1} / \mathrm{T}_{\mathrm{h} 2}$-type responses as a consequence of boosting with specific antigen [33]. Specific anti-fugu CD4 antibodies (Abs) were produced to isolate $\mathrm{CD} 4^{+} \mathrm{T}$ cells from Japanese puffer fish, Fugu rubripes, and characterize their cytokine expression profile [34]. It was found that several distinct $\mathrm{T}_{h}$ cytokines were expressed in fugu $\mathrm{CD} 4^{+}$ $\mathrm{T}$ cells and these cells expressed T-cell marker genes but not macrophage or B-cell marker genes. Based on the 
results of these experiments, it was suggested that $T_{h}$ subsets exist in fish and that the orientation of immune responses is regulated by $T_{h}$ cytokines expressed from the cells, as occurs in mammals.

\section{$5 \mathrm{CD4}^{+} \mathrm{T}$ cell subtypes}

Subsequent to interaction with the antigen-MHC complex, the naive $\mathrm{CD}^{+}{ }^{+} \mathrm{T}$ cells get activated and differentiate into specific subtypes, namely, T-helper 1, T-helper 2, T-helper 9, T-helper 17, and induced regulatory- $\mathrm{T}$ cells, each with a characteristic cytokine profile [35]. The mechanism through which the $\mathrm{CD} 4^{+}$cells tackle different pathogens has been elucidated previously. $T_{h} 1, T_{h} 2$, $T_{h} 17, T_{h} 9$, and iTreg cells delineate the division of labor of the $\mathrm{CD}^{+}$cells (Figure 2) for governing a particular immune response [9]. This control over the immune system is based on the production of different types of cytokines, such as IFN- $\alpha$, TGF- $\beta-1$, IL-4, and IL-17, similar to mammals [6]. Each $\mathrm{CD}^{+}{ }^{+}$T-helper cell possesses a characteristic ability to respond to a particular cytokine (inductive) and processes it via selective master transcription factors, and in turn produces another set of cytokines (functional) in order to perform its roles $[36,37]$. Studies investigating cytokines, particularly the interleukin (IL) category, in fish have been reported and published previously [38]. When a pathogen intrudes into the body, the $\mathrm{T}$ helper cells-related cytokines are generated, which then modulate the inflammatory signals to control phagocytes and annihilate the invading antigen. These cytokines also regulate the antigen-presenting cells (APC) in order to commence the adaptive immune response $[39,40]$. The differentiation of different lineages of immune cells depends on the complex network of specific cytokine signaling and transcription factors, followed by epigenetic modifications [41, 42].

\section{Potential factors for differentiation of $\mathrm{CD}^{+} \mathrm{T}$ cell subtypes in fish}

\section{1 $\mathrm{T}_{h} 1$ cell differentiation}

The T-cell differentiation process is primarily initiated by cytokine signals generated by APC subsequent to the encounter with pathogens [43]. In mammals, IL-12 and interferon (IFN- $\gamma$ ) are the key cytokines responsible for $\mathrm{T}_{\mathrm{h}} 1$ differentiation, through the regulation of several transcription factors including the T-bet master regulator, signal transducer and activator of transcription-1 (STAT-1), and STAT-4. Subsequent to antigen interaction, APC (mostly dendrites) release huge amounts of IL-12, which is captured by the naive $\mathrm{CD} 4^{+} \mathrm{T}$ cells, following which IFN- $\gamma$ is released [14]. Within the site of both IFN- $\gamma$ and IL-12, STAT-1 and STAT-4 trigger T-bet expression. T-bet subsequently invigorates the

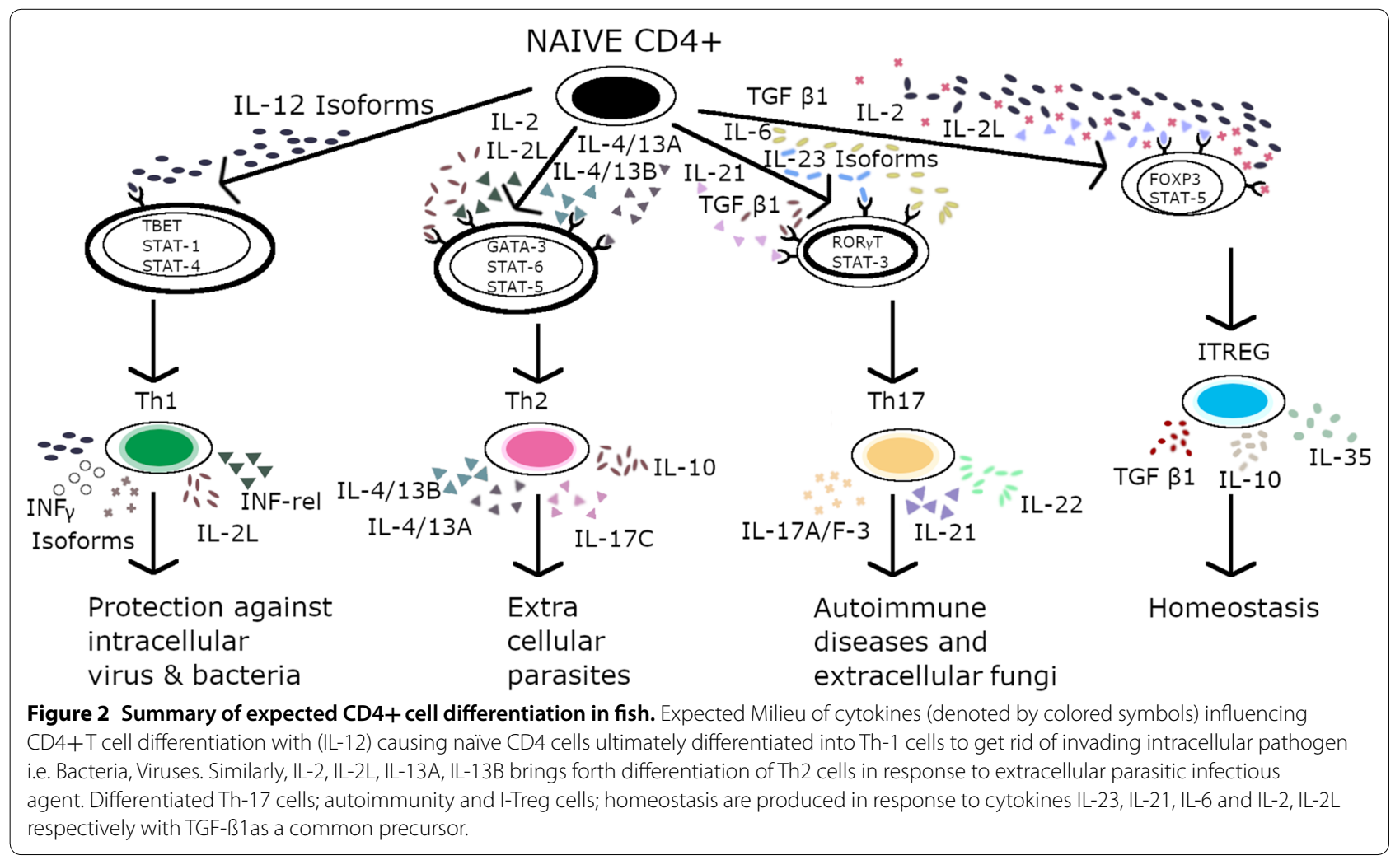


IFN- $\gamma$ production by the differentiated $\mathrm{T}$ cells, consequently amplifying the T-bet expression and strengthening the selective differentiation of $T_{h} 1$ cells via the expression of IL-12 [44]. T-bet, also known as Tbx 21 , is responsible for type-1 (cell-mediated) immunity in almost all the immune cells of the innate as well as specific immunity. The T-bet gene has been identified in rainbow trout [45], grass carp [36], and zebrafish [37]. In an investigation involving rainbow trout, it was established that T-bet is expressed equally in the spleen and head kidney; although a strong expression of T-bet has been reported in the peripheral blood leukocytes, spleen, and head kidney following bacterial and parasitic infections. It was suggested that $\mathrm{T}$-bet plays a crucial role in performing in cell-mediated immunity in the teleost fish, as its expression was found to be upregulated with the use of $\mathrm{T}$ cell-stimulant phytohemagglutinin (PHA). In fish, multiple isoforms of IL-12 [not just single IL-12] and IFN- $\gamma$-rel [instead of IFN- $\gamma$ ] are considered to be the main cytokine drivers for a possible $\mathrm{T}_{\mathrm{h}} 1$ differentiation; also, two particular isoforms, viz., IL-2 and IL-2L, have been documented to date $[13,46]$. However, the master transcription factors are considered to be the same in fish and mammals both, for example, T-bet along with its assisting transcription factors STAT- 1 and STAT-4 [47].

IL-12 (heterodimeric cytokine with p35 and p40 subunits) is a type of interleukin produced mostly by macrophages, dendrites, and neutrophils subsequent to interaction with an antigen; this cytokine affects the $\mathrm{CD}^{+}{ }^{+} \mathrm{T}_{\mathrm{h}} 1$ cell differentiation. IL-12 possesses the ability to increase the cytolytic activity of natural killer cells and $\mathrm{T}$ cells [48]. Fish p35 and p40 subunits were first identified in fugu [13]. In common carp and sea bass, the single p35 gene has been documented. The p35 subunit of IL-12 is not as expressive in fish as it is in mammals, with restricted expression at sites such as the thymus and gills and unrestricted expression in blood, head kidney, and spleen. However, following viral and bacterial exposure, the expression of the p35 subunit was reported to be upregulated in the common carp [27]. It was also propounded that the $\mathrm{p} 40$ gene in fish exhibits different isoforms, viz., 40a, 40b, and 40c, and that the p40a isoform demonstrates greater homology to the mammalian gene compared to the other isoforms. It was observed that the p40 subunit of IL-12 was expressed more in all tissues compared to the p35 subunit; the expression of the isoforms of p40 differed in different tissues following a viral infection, and p40c was not expressed in the thymus of fish [4]. The presence of IL-12 isoforms may propound the necessity of additional studies in order to investigate these different isoforms and explore the ways in which these isoforms successfully control $\mathrm{T}_{\mathrm{h}} 1$ differentiation as well as the other functions involved in the fish immune response.

IFN subtypes produced by the $\mathrm{CD}^{+} \mathrm{T}_{\mathrm{h}} 1$ cells are imperative for both adaptive and acquired immunity, as they provide the antiviral ability to the cells. There are three classes of IFN-I, II, and III; fish IFN- $\gamma$ belongs to class II. The IFN- $\gamma$ gene was first reported in fugu, [49], followed by zebrafish [50] and Atlantic salmon [51]. Teleost-specific IFN- $\gamma$-rel reported in zebrafish and fugu was observed to be different in comparison to IFN- $\gamma$ in the other fish species [13]; consequently, two subtypes of IFN (IFN- $\gamma$ and IFN- $\gamma$-rel) have been documented in bony fish.

Although the exact evidence of the presence of $T_{h} 1$ differentiation in fish has not been completely established, the upregulation of IFN- $\gamma$, IL-12, and T-Bet expression subsequent to the induction of the infection model or vaccination in rainbow trout, and the correlation of T-bet expression with IFN- $\gamma$ production indicates events associated with $\mathrm{T}_{\mathrm{h}} 1$ regulation.

\section{2 $\mathrm{CD}^{+} \mathrm{T}_{\mathrm{h}} 2$ cell differentiation}

Unlike the $T_{h} 1$ cells that are responsible for type-1 immunity, $\mathrm{T}_{\mathrm{h}} 2$ cells stimulate the production of antibodies by inducing IL-4, IL-10, IL-13, and IL-25, which are accountable for the proliferation of B lymphocytes [52]. It has also been observed that in the presence of parasitic infestation or venoms, IL-5, IL-9, and IL-13 are released, stimulating the mast cells, and a cascade of allergic reactions that follow. The strength of the signals via TCR is essential as it governs the differentiation between $T_{h} 1$ and $T_{h} 2$ cells; stronger signals initiate $T_{h} 1$ differentiation, while weaker signals cause $\mathrm{T}_{\mathrm{h}} 2$ differentiation [53]. According to investigations, low-frequency signals cause the T-cells to promptly induce the expression of $\mathrm{T}_{h} 2$ master regulatory transcription factor GATA3, which leads to IL-2 production. This eventually activates STAT- 5 via IL-4Ra expression and IL-4 is produced as a result of the dimerization of STAT- 6 caused by STAT5 and GATA3 activation. STAT-5 activation may drive the effector cytokines to be fully expressed, resulting in $\mathrm{T}_{h} 2$ cells; therefore, IL- 4 is the key cytokine for $\mathrm{T}_{h} 2$ cell development. Similarly, in fish, two IL-4-like genes have been documented in tetraodon [38]. Since these genes were related to IL-13, they were named IL-4/13A and IL-4/13B [54]. These isoforms are considered the precursors for $\mathrm{T}_{\mathrm{h}} 2$ cell development and antibody production, just as in mammals. IL-4/13A induces the production of immunoglobulin-producing cells in zebrafish, causing antibody production. Similarly, two isoforms of IL-2 have been isolated from fish, namely, IL-2 and IL-2L. IL-2 has been discovered in lower vertebrates and the existence of the IL-2 gene was recognized through genome analysis [55]. 
The authors reported that in response to mitogen PHA, trout IL-2 was drastically upregulated in the head kidney leucocytes in a mixed-lymphocyte reaction controlled by STAT-5 transcription factor. In mammals, an IL-7-like cytokine, known as the thymic stromal lymphopoietin (TSLP), has been identified. It causes IL-4 to induce the development of $\mathrm{T}_{h} 2$ cells. So far, there has been no evidence of the TSLP gene in fish, inviting fresh research initiatives to explore novel genes involved in $T_{h} 2$ differentiation. Similarly, IL-25 and IL-17 are also considered to have a role in the activation and differentiation of $\mathrm{T}_{h} 2$ cells, through the production of IL- 4 and by exhibiting an inhibitory effect on the $T_{h} 1$ cells [40]. Mammalian IL-25/ IL-33 has not yet been detected in any of the teleost fish species. In addition to STAT-3, STAT-5, and STAT-6, the transcription factor GATA3 is a master regulator for $\mathrm{T}_{\mathrm{h}} 2$ differentiation, and its expression is decreased during $\mathrm{T}_{\mathrm{h}} 1$ differentiation. STAT- 5 requires a signal from IL-2 via IL-4Ra expression, and STAT-6 requires IL-4 for its activation. In CD4 ${ }^{+} \mathrm{T}$ cells, GATA3 is responsible for the downregulation of IFN- $\gamma$ and $\mathrm{T}_{\mathrm{h}} 1$ differentiation, in addition to its regular functions of $\mathrm{T}_{\mathrm{h}} 2$ development and cytokine production [56]. GATA3 has been identified and isolated from different species of fish, including zebrafish [57], salmonids [58], and grass carp [36]. Interestingly, the expression of GATA3 and T-bet in trout was increased by PHA, signifying their presence in the activated $T$ cells, particularly in the spleen, following the induction of infection [59]. Certain bacteria (e.g., Yersinia ruckeri) were able to downregulate the production of both GATA3 and T-bet in fish through mechanisms that suppressed the host immune system [45]. In summary, the presence of IL-4/13 and GATA3 along with STAT5 and STAT6 in fish emphasizes the requirement for further investigation on $\mathrm{T}_{\mathrm{h}} 2$ differentiation.

\section{3 $\mathrm{CD}^{+} \mathrm{T}_{\mathrm{h}} 17$ differentiation}

T-helper 17 cells $\left(T_{h} 17\right.$ cells) have been reported to be important for the prevention of autoimmune disorders, due to their ability to serve either as protective/nonpathogenic cells or proinflammatory pathogenic cells. $\mathrm{T}_{\mathrm{h}} 17$ cells are characterized by IL- 17 production. $\mathrm{T}_{\mathrm{h}} 17$ cells are considered to be closely related to iTreg cells, and the differentiation of these two cells is inversely proportional. $T_{h} 17$ cells are the protective cells that maintain and guard the mucosal surface against microbial populations. IL-6, IL-21, IL-23, and TGF- $\beta$ are responsible for the segregation of $T_{h} 17$ cells, along with the key precursors such as retinoic acid receptor-related orphan receptors gamma (ROR $\gamma)$ and alpha (ROR $\alpha)$ and the signal transducer and activator of transcription 3 (STAT3) [41]. IL- 6 and TGF- $\beta$ stimulate the production of a nonpathogenic type of $T_{h} 17$ cells, while IL-23 and IL-1 $\beta$ are accountable for the production of a pathogenic type of $\mathrm{T}_{\mathrm{h}} 17$ cells [39]. The main effectors or signature cytokines IL-17A, IL-17F, IL-21, and IL-22 are responsible for all the functions of the $T_{h} 17$ cells [40]. IL-21 secreted by $\mathrm{T}_{\mathrm{h}} 17$ cells during differentiation collaborates with TGF- $\beta$ to further increase the production of STAT3-dependent IL-17 and the expression of IL-23R. IL-23 is necessary for the expansion and continuance of the $\mathrm{T}_{\mathrm{h}} 17$ population.

$\mathrm{T}_{\mathrm{h}} 17$ cells produce IL-17A and IL-17F, and their expression is controlled by RORyt and STAT3 [41]. RORyt is stimulated by either IL- 6 or IL-21, with the help of TGF- $\beta$, and for the activation of STAT3 also, IL-23 is required along with IL-6 or IL-21 [42]. An orthologous gene ROR $\gamma$, instead of ROR $\gamma \mathrm{t}$, has been reported in rainbow trout [60]. Three isoforms of IL-17A/F genes, namely, IL-17A/F1, IL-17A/F2, and IL-17A/F3, have been identified in zebrafish [61], rainbow trout [62], fugu [63] and turbot (Scophthalmus maximus) [64]. The basal expression of these three isoforms has been reported to be different on the tissue level. IL-17A/F1 in turbot was reported to be highly expressed in head kidney, intestine, and gills. While in trout, IL-17A/F2 was observed to be expressed less in the head kidney in comparison to the gills and intestine [62].

Similarly, the IL-6 gene has been reported in the rainbow trout [65], Japanese flounder [66] and other teleosts [67]. In the above-mentioned publications, the IL-6 gene expression was upregulated following the immune stimulation, compared to normal conditions, in the spleen and brain of rainbow trout. IL-6 in trout was able to promote macrophage growth through the induction of phosphorylation of STAT3 formed during the events of the inflammatory response.

IL-21 has been reported to be expressed by activated T cell and is not present normally in the tissues; it has been indicated to cause $\mathrm{T}_{\mathrm{h}} 17$ differentiation via IL-23R expression [68]. IL-21 has been discovered in fugu [69], rainbow trout and other teleosts [70]. Unlike the mammalian IL-23, multiple isoforms of IL-23 have been reported in zebrafish [69].

Most of the elements of mammalian $\mathrm{T}_{\mathrm{h}} 17$ cell differentiation machinery are also present in fish, including the master transcription factors such as IL-6, TGF- $\beta-1$, IL-21, and IL-23, which is suggestive of the presence of $\mathrm{T}_{\mathrm{h}} 17$ cells-like response in fish as well.

\section{4 $\mathrm{CD}^{+}$regulatory $\mathrm{T}$ cell differentiation}

As the name suggests, regulatory $\mathrm{T}$ cells (Tregs), also known as suppressor $T$ cells, are the subset of helper $T$ cells that regulate the immune response, preserve the tolerance of internal structures to self-antigens, and provide protection against autoimmune diseases [71]. It has been perceived that the cytokines TGF- $\beta$ and IL-10 are 
responsible for the differentiation of Treg cells as well as for Treg homeostasis [72]. Forkhead box P3 (FoxP3) expression factor is a crucial asset that determines the natural functions of Treg cells [71]. Tregs were first documented along with FoxP3 expression factor in 2003 and were perceived as essential for the inflammatory responses [73]. In brief, Treg cells control the enormity of immune responses to infectious agents and tumors. Similar to the mammalian TGF- $\beta$ family, different TGF- $\beta$ isoforms (e.g., TGF- $\beta-3$ ) exist in fish. Fish also contain TGF- $\beta-1$, which was first reported in rainbow trout [69]. Besides IL-6, TGF- $\beta-1$ also causes $T_{h} 17$ cell differentiation, in addition to maintaining the inflammatory environment, suppressing the differentiation of $T_{h} 1$ and $T_{h} 2$ cells, and initiating the FoxP3 ${ }^{+}$Tregs to defend against autoimmune diseases [74]. Alongside the documentation of all the three isoforms of TGF- $\beta$ (e.g., TGF- $\beta$ - 3 ) in fish [75], another gene type TGF- $\beta-6$ has been identified in gilthead sea bream. Although IL-10 is produced by all types of $\mathrm{CD}^{+}$cells, Treg cells are the key source of this cytokine [72]. Interleukin-10-type gene was first recognized in fugu [76], and to date, its two isoforms IL-10a and IL-10b have been identified in rainbow trout [77], zebrafish [78], sea bass [79], grass carp [80], and goldfish [81]. The master transcription factor of Tregs (FoxP3) is required for the immunosuppressive activity and fitness of Tregs. The inducible FoxP3 has been discovered in salmonids [59], grass carp [80], and tetraodon [82], with a little dissimilarity with the mammalian FoxP3 gene which is suggestive of a different mechanism of regulation in fish.

\section{$7 \mathrm{CD4}^{+} \mathrm{T}$ cell response against pathogens}

On the basis of the documented cytokines in fish, the expected cytokine production may be hypothesized using the already-available mammalian paradigm. As stated earlier, cytokines such as IFN- $\gamma$, IL-4/13, IL-2, IL$17 \mathrm{~A} / \mathrm{F}$, and IL-10 in fish share homology with the mammalian IL-13, IL-4, IL-17A, and IL-17F, respectively. In fish, a wide range of disorders prevails, several of them infectious in nature, and others being autoimmune disorders [83]. When the antimicrobial activity of the $T_{h} 1$ and $T_{h} 2$ cells was first documented, these cells were perceived to manage infection, limiting its growth and disastrous effect [84]. $T_{h} 1$ cells govern the protective response against the intracellular pathogens such as bacteria, fungi, and protozoa; while, with viruses, the immune response is governed by B-lymphocytes and $\mathrm{CD}^{+}$cells [84]. $\mathrm{T}_{\mathrm{h}} 1$ cells are effective against the intracellular antigen, causing the release of IFN $\gamma$ and IL-2 [14]. Therefore, the same may be expected in the fish immune system, considering the aforementioned presence of $T_{h} 1$ cytokines, as cytokines are the markers for $T_{h} 1$ characterization. In mammals, IL-12 triggers the immune response against intracellular pathogens, causing $\mathrm{T}_{\mathrm{h}} 1$ polarization and alerting the other components of the immune system [84] to respond accordingly; the same may be expected in fish, however, with the IL-12 isoform inducing the IFN- $\gamma$ isoforms and executing the signaling. This response to a pathogen may cause a little pathological inflammation, which is controlled by iTreg cells that produce TGF- $\beta-1$ and IL-10 in order to downregulate the $\mathrm{T}_{\mathrm{h}} 1$ activity. This phenomenon is equivalent to that observed in mammals. In helminths, $\mathrm{T}_{\mathrm{h}} 2$ cells act as officers in command, activated by IL- 2 and IL- 4 [different isoforms of these cytokines in fish], producing the driver cytokines IL-10 and IL-13 [different isoforms of these cytokines in fish] to activate the eosinophils and mast cells and to induce the production of IgE ( $\mathrm{T}_{\mathrm{h}} 2$-dependent antibodies) for the elimination of the invader [84]. $\mathrm{T}_{\mathrm{h}} 17$ cells are involved in protection against the extracellular bacterial or fungal infection. Treg cells regulate the actions of $T_{h} 1, T_{h} 2$, and $\mathrm{T}_{\mathrm{h}} 17$ cells, and are responsible for peripheral tolerance [43]. Treg cells, also known as $\mathrm{CD}^{+} \mathrm{CD}^{2} 5^{+} \mathrm{FoxP}^{+}$regulatory $\mathrm{T}$ cells, are accountable for the insensitive immunological response to self-antigens, expression of foxhead box $\mathrm{p} 3$ (foxp3), and the maintenance of the host immune response to a favorable/healthy level. Different phenotypes of Treg cells, namely, CD4-like- $2^{+}$, CD25-like ${ }^{+}$, and Foxp3-like ${ }^{+}$, have been reported in pufferfish [85].

\section{Conclusions}

This review discusses the possible existence of $C D 4^{+} T_{h}$ cell differentiation in fish, as well as the molecular characterization of $\mathrm{CD} 4$ based on the documented facts. The mammalian paradigm for T-helper subset segregation appeared to have rather a similar machinery and cytokines, although these are just dubious evidence. The adaptive immune system in fish is imperative for both natural immunity and vaccine-induced immunity; therefore, greater knowledge regarding this system will enable achieving greater protection against a particular organism. The efficiency of vaccine development is influenced largely by the production of cytokines, which are considered the most suitable markers for the evaluation of a particular vaccine. Therefore, this review paves the way for the development of strategies for monitoring a strong immune response against a particular pathogen. It is time to utilize our acquaintance with the $\mathrm{T}$ cell subpopulation, and develop a novel therapeutic approach for fish, just as in mammals. This review also provides insights into the cytokine network necessary for an early adaptive immune response.

The molecular characterization of CD4 has led to the awareness that different domains and subtypes of CD4 are present in fish, similar to mammals. If the mechanism 
of antigen binding is compared, mammals contain binding sites that are different from those in fish, although the cytoplasmic Lck and the Ig-like domains are nonetheless present. It may be hypothesized that fish share the same mechanism of antigen attachment as in mammals, with only minor differences. Molecular characterization of CD4 in fish offers imminent advancement of research, through gene expression data, in order to identify the cell-surface markers and proteins coding for $\mathrm{T}_{h}$ populations. Further research is required to accurately understand the pathways that lead to the creation of these CD4 ${ }^{+} \mathrm{T}_{\mathrm{h}}$ cells as well as the preferential expansion of the $\mathrm{T}$-cell subset capable of mediating a protective response. Finally, we have to point out that even though there are similarities between fish and upper vertebrate immune regulatory networks, there is not nearly as much hard evidence to support speculative statements and research requests.

\begin{abstract}
Abbreviations
APCS: antigen-presenting cells; RAG: recombination activating gene; CTLS: cytotoxic T-lymphocytes; TH: Thelper cells; GATA: proteins recognize G-A-T-A nucleotide/types; IFNs: interferon types; ROR: retinoic acid receptor-related orphan receptors gamma; T-BET: transcription factor; STAT: signal transducer and activator of transcription-types; TCR: T-cell receptor; MHC: major histocompatibility complex; TSLP: thymic stromal lymphopoietin; CXC: chemokine receptor; FOXP3: forkhead box P3 transcription factor; CYS: cysteine; IG: immunoglobulins; MALT: mucosa-associated lymphoid tissues; IL: interleukins; ITREG: induced regulatory T cells; LCK: lymphocyte-specific protein tyrosine kinase; T-BOX: transcrpition factor; PHA: phytohaemagglutinin; TGF-ß1: transforming growth factor beta 1 .
\end{abstract}

\section{Competing interests}

The authors declare that they have no competing interests.

\section{Authors' contributions}

MEM, HS and MS designed the structure of the review; HA drafted the manuscript and prepared the figure; MEM, HS, and MS critically revised the manuscript. All authors read and approved the final manuscript.

\section{Acknowledgements}

The first author thanks the Higher Education Commission of Pakistan for providing Ph.D. scholarship to study abroad.

\section{Funding}

This study was funded by the University of Veterinary Medicine, Vienna (PP291-ELM), and the Austrian Science Fund (FWF) Project No. P29294-B25.

\section{Publisher's Note}

Springer Nature remains neutral with regard to jurisdictional claims in published maps and institutional affiliations.

Received: 13 July 2018 Accepted: 21 November 2018

Published online: 07 January 2019

\section{References}

1. Kasheta M, Painter CA, Moore FE, Lobbardi R, Bryll A, Freiman E, Stachura $D$, Rogers AB, Houvras Y, Langenau DM, Ceol CJ (2017) Identification and characterization of T reg-like cells in zebrafish. J Exp Med 214:3519-3530
2. Dixon B, Stet RJ (2001) The relationship between major histocompatibility receptors and innate immunity in teleost fish. Dev Comp Immunol 25:683-699

3. Kato G, Goto K, Akune I, Aoka S, Kondo H, Hirono I (2013) CD4 and CD8 homologues in Japanese flounder, Paralichthys olivaceus: differences in the expressions and localizations of CD4-1, CD4-2, CD8a and CD8ß. Dev Comp Immunol 39:293-301

4. Forlenza M, de Carvalho Dias JDA, Veselý T, Pokorová D, Savelkoul HFJ, Wiegertjes GF (2008) Transcription of signal-3 cytokines, IL-12 and IFNaß, coincides with the timing of $\mathrm{CD} 8 \mathrm{a} \beta$ up-regulation during viral infection of common carp (Cyprinus carpio L.). Mol Immunol 45:1531-1547

5. Oladiran A, Beauparlant D, Belosevic M (2011) The expression analysis of inflammatory and antimicrobial genes in the goldfish (Carassius auratus L.) infected with Trypanosoma carassii. Fish Shellfish Immunol 31:606-613

6. Saito S, Nakashima A, Shima T, Ito M (2010) Th1/Th2/Th17 and regulatory T-Cell paradigm in pregnancy. Am J Reprod Immunol 63:601-610

7. Dupage M, Bluestone JA (2016) Harnessing the plasticity of CD4+T cells to treat immunemediated disease. Nat Rev Immunol 16:149-163

8. Laing KJ, Zou JJ, Purcell MK, Phillips R, Secombes CJ, Hansen JD (2006) Evolution of the CD4 family: teleost fish possess two divergent forms of CD4 in addition to lymphocyte activation gene-3. J Immunol 177:3939-3951

9. Ziegler SF (2016) Division of labour by CD4+T helper cells. Nat Rev Immunol 16:403

10. Dee CT, Nagaraju RT, Athanasiadis El, Gray C, del Ama LF, Johnston SA, Secombes CJ, Cvejic A, Hurlstone AF (2016) CD4-transgenic zebrafish reveal tissue-resident Th2-and regulatory T cell-like populations and diverse mononuclear phagocytes. J Immunol 197:3520-3530

11. Dijkstra JM, Grimholt U, Leong J, Koop BF, Hashimoto K (2013) Comprehensive analysis of MHC class II genes in teleost fish genomes reveals dispensability of the peptide-loading DM system in a large part of vertebrates. BMC Evol Biol 13:260

12. Robertsen $B$ (2006) The interferon system of teleost fish. Fish Shellfish Immunol 20:172-191

13. Yoshiura Y, Kiryu I, Fujiwara A, Suetake H, Suzuki Y, Nakanishi T, Ototake M (2003) Identification and characterization of Fugu orthologues of mammalian interleukin-12 subunits. Immunogenetics 55:296-306

14. Luckheeram RV, Zhou R, Verma AD, Xia B (2012) CD4+T cells: differentiation and functions. Clin Dev Immunol 2012:925135

15. Nayak SK, Nakanishi T (2013) Direct antibacterial activity of CD8+/ CD4+T-cells in ginbuna crucian carp, Carassius auratus langsdorfii. Fish Shellfish Immunol 34:136-141

16. Maddon PJ, Molineaux SM, Maddon DE, Zimmerman KA, Godfrey M, Alt FW, Chess L, Axel R (1987) Structure and expression of the human and mouse T4 genes. Proc Natl Acad Sci U S A 84:9155-9159

17. Weiss A, Littman DR (1994) Signal transduction by lymphocyte antigen receptors. Cell 76:263-274

18. Koskinen R, Salomonsen J, Tregaskes CA, Young JR, Goodchild M, Vainio O, Bumstead N (2002) The chicken CD4 gene has remained conserved in evolution. Immunogenetics 54:520-525

19. Wange RL, Samelson LE (1996) Complex complexes: signaling at the TCR. Immunity 5:197-205

20. Moore LJ, Dijkstra JM, Koppang EO, Hordvik I (2009) CD4 homologues in Atlantic salmon. Fish Shellfish Immunol 26:10-18

21. Stet RJ, De Vries B, Mudde K, Hermsen T, Van Heerwaarden J, Shum BP, Grimholt U (2002) Unique haplotypes of co-segregating major histocompatibility class II A and class II B alleles in Atlantic salmon (Salmo salar) give rise to diverse class II genotypes. Immunogenetics 54:320-331

22. Suetake H, Araki K, Suzuki Y, Hordvik I, Ototake M, Fischer U (2004) Cloning, expression, and characterization of fugu CD4, the first ectothermic animal CD4. Immunogenetics 56:368-374

23. Dijkstra JM, Somamoto T, Moore L, Hordvik I, Ototake M, Fischer U (2006) Identification and characterization of a second CD4-like gene in teleost fish. Mol Immunol 43:410-419

24. Edholm ES, Stafford JL, Quiniou SM, Waldbieser G, Miller NW, Benten E, Wilson M (2007) Channel catfish, Ictalurus punctatus, CD4-like molecules. Dev Comp Immunol 31:172-187

25. Buonocore F, Randelli E, Casani D, Guerra L, Picchietti S, Costantini S, Facchiano AM, Zou J, Secombes CJ, Scapigliati G (2008) A CD4 homologue in sea bass (Dicentrarchus labrax): molecular characterization and structural analysis. Mol Immunol 45:3168-3177 
26. Nonaka S, Somamoto T, Kato-Unoki Y, Ototake M, Nakanishi T, Nakao M (2008) Molecular cloning of CD4 from ginbuna crucian carp Carassius auratus langsdorfii. Fish Sci 74:341-346

27. Sun X-F, Shang N, Hu W, Wang Y-P, Guo Q-L (2007) Molecular cloning and characterization of carp (Cyprinus carpio L.) CD8ß and CD4-like genes. Fish Shellfish Immunol 23:1242-1255

28. Patel S, Øvergård AC, Nerland AH (2009) A CD4 homologue in Atlantic halibut (Hippoglossus hippoglossus): molecular cloning and characterisation. Fish Shellfish Immunol 26:377-8432

29. Øvergård AC, Nerland AH, Patel S (2010) Cloning, characterization, and expression pattern of Atlantic halibut (Hippoglossus hippoglossus L.) CD42, Lck, and ZAP-70. Fish Shellfish Immunol 29:987-997

30. Takizawa F, Madagan S, Parra D, Xu Z, Korytáŕ T, Boudinot P, Sunyer O (2016) Novel teleost CD4-bearing cell populations provide insights into the evolutionary origins and primordial roles of CD4+ lymphocytes and CD4+ macrophages. J Immunol 196:4522-4535

31. Toda H, Saito Y, Koike T, Takizawa F, Araki K, Yabu T, Somamoto T, Suetake H, Suzuki Y, Ototake M, Moritomo T (2011) Conservation of characteristics and functions of CD4 positive lymphocytes in a teleost fish. Dev Comp Immunol 35:650-656

32. Rebello SC, Rathore G, Punia P, Sood N (2016) Development and characterization of a monoclonal antibody against the putative T cells of Labeo rohita. Cytotechnology 68:469-480

33. Yoon S, Mitra S, Wyse C, Alnabulsi A, Zou J, Weerdenburg EM, van der Sar AM, Wang D, Secombes CJ, Bird S (2015) First demonstration of antigen induced cytokine expression by CD4-1+ lymphocytes in a poikilotherm: studies in zebrafish (Danio rerio). PLoS One 10:e0126378

34. Kono T, Korenaga $\mathrm{H}$ (2013) Cytokine gene expression in CD4 positive cells of the Japanese pufferfish. Takifugu rubripes. PLoS One 8:e66364

35. Abbas AK, Murphy KM, Sher A (1996) Functional diversity of helper T lymphocytes. Nature 383:787-793

36. Wang L, Shang N, Feng H, Guo Q, Dai H (2013) Molecular cloning of grass carp (Ctenopharyngodon idellus) T-bet and GATA-3, and their expression profiles with IFN- $\gamma$ in response to grass carp reovirus (GCRV) infection. Fish Physiol Biochem 39:793-805

37. Mitra S, Alnabulsi A, Secombes CJ, Bird S (2010) Identification and characterization of the transcription factors involved in T-cell development, t-bet, stat6 and foxp3, within the zebrafish, Danio rerio. FEBS 277:128-147

38. Li JH, Shao JZ, Xiang LX, Wen Y (2007) Cloning, characterization and expression analysis of pufferfish interleukin-4 CDNA: the first evidence of Th2-type cytokine in fish. Mol Immunol 44:2088-2096

39. Singh B, Schwartz JA, Sandrock C, Bellemore SM, Nikoopour E (2013) Modulation of autoimmune diseases by interleukin (IL)-17 producing regulatory T helper (Th17) cells. Indian J Med Res 138:591-594

40. Annunziato F, Romagnani S (2009) Heterogeneity of human effector CD4+T cells. Arthritis Res Ther 11:257

41. Zhu J, Yamane H, Paul WE (2009) Differentiation of effector CD4T cell populations. Annu Rev Immunol 28:445-489

42. Zhu J, Paul WE (2009) CD4 T cells: fates, functions, and faults. Immunobiology 112:1557-1569

43. Yamane H, Paul WE (2013) Early signaling events that underlie fate decisions of naive CD4+T cells toward distinct T-helper cell subsets. Immunol Rev 252:12-23

44. Oestreich KJ, Weinmann AS (2012) T-bet employs diverse regulatory mechanisms to repress transcription. Trends Immunol 33:78-83

45. Wang T, Holland JW, Martin SAM, Secombes CJ (2010) Sequence and expression analysis of two T helper master transcription factors, T-bet and GATA3, in rainbow trout Oncorhynchus mykiss and analysis of their expression during bacterial and parasitic infection. Fish Shellfish Immunol 29:705-715

46. Nascimento DS, do Vale A, Tomás AM, Zou J, Secombes CJ, dos Santos NMS (2007) Cloning, promoter analysis and expression in response to bacterial exposure of sea bass (Dicentrarchus labrax L.) interleukin-12 p40 and p35 subunits. Mol Immunol 44:2277-2291

47. Gorissen M, de Vrieze E, Flik G, Huising MO (2011) STAT genes display differential evolutionary rates that correlate with their roles in the endocrine and immune system. J Endocrinol 209:175-184

48. Park JY, Lee SH, Yoon SR, Park YJ, Jung H, Kim TD, Choi I (2011) IL-15-induced IL-10 increases the cytolytic activity of human natural killer cells. Mol Cells 32:265-272
49. Zou J, Yoshiura Y, Dijkstra JM, Sakai M, Ototake M, Secombes C (2004) Identification of an interferon gamma homologue in Fugu, Takifugu rubripes. Fish Shellfish Immunol 17:403-409

50. Igawa D, Sakai M, Savan R (2006) An unexpected discovery of two interferon gamma-like genes along with interleukin (IL)-22 and -26 from teleost: LL-22 and - 26 genes have been described for the first time outside mammals. Mol Immunol 43:999-1009

51. Robertsen B, Bergan V, Røkenes T, Larsen R, Albuquerque A (2003) Atlantic salmon interferon genes: cloning, sequence analysis, expression, and biological activity. J Interferon Cytokine Res 23:601-612

52. Punnonen J, de Vries JE (1994) IL-13 induces proliferation, Ig isotype switching, and Ig synthesis by immature human fetal B cells. J Immunol 152:1094-1102

53. Constant SL, Bottomly K (1997) Induction of Th1 and Th2 CD4+T cell responses: the alternative approaches. Annu Rev Immunol 15:297-322

54. Ohtani M, Hayashi N, Hashimoto K, Nakanishi T, Dijkstra JM (2008) Comprehensive clarification of two paralogous interleukin $4 / 13$ loci in teleost fish. Immunogenetics 60:383-397

55. Díaz-Rosales P, Bird S, Wang TH, Fujiki K, Davidson WS, Zou J, Secombes CJ (2009) Rainbow trout interleukin-2: cloning, expression and bioactivity analysis. Fish Shellfish Immunol 27:414-422

56. Yagi R, Zhu J, Paul WE (2011) An updated view on transcription factor GATA3-mediated regulation of Th1 and Th2 cell differentiation. Int Immunol 23:415-420

57. Neave B, Rodaway A, Wilson SW, Patient R, Holder N (1995) Expression of zebrafish GATA 3 (gta3) during gastrulation and neurulation suggests a role in the specification of cell fate. Mech Dev 51:169-182

58. Kumari J, Bogwald J, Dalmo RA (2009) Transcription factor GATA-3 in Atlantic salmon (Salmo salar): molecular characterization, promoter activity and expression analysis. Mol Immunol 46:3099-3107

59. Wang T, Monte MM, Huang W, Boudinot P, Martin SAM, Secombes C (2010) Identification of two FoxP3 genes in rainbow trout (Oncorhynchus mykiss) with differential induction patterns. Mol Immunol 47:2563-2574

60. Monte MM, Wang T, Costa M, Harun O, Secombes CJ (2012) Cloning and expression analysis of two ROR- $\gamma$ homologues (ROR-ya1 and ROR-ya2) in rainbow trout Oncorhynchus mykiss. Fish Shellfish Immunol 33:365-374

61. Gunimaladevi I, Savan R, Sakai M (2006) Identification, cloning and characterization of interleukin-17 and its family from zebrafish. Fish Shellfish Immunol 21:393-403

62. Monte MM, Wang T, Holland JW, Zou J, Secombes CJ (2013) Cloning and characterization of rainbow trout interleukin-17A/F2 (IL-17A/F2) and IL-17 receptor $\mathrm{A}$ : expression during infection and bioactivity of recombinant IL-17A/F2. Infect Immun 81:340-353

63. Kono T, Bird S, Sonoda K, Savan R, Secombes CJ, Sakai M (2008) Characterization and expression analysis of an interleukin-7 homologue in the Japanese pufferfish, Takifugu rubripes. FEBS J 275:1213-1226

64. Costa MM, Pereiro P, Wang T, Secombes CJ, Figueras A, Novoa B (2012) Characterization and gene expression analysis of the two main Th17 cytokines (IL-17A/F and IL-22) in turbot, Scophthalmus maximus. Dev Comp Immunol 38:505-516

65. Iliev DB, Castellana B, Mackenzie S, Planas JV, Goetz FW (2007) Cloning and expression analysis of an IL-6 homolog in rainbow trout (Oncorhynchus mykiss). Mol Immunol 44:1814-1818

66. Bird S, Zou J, Savan R, Kono T, Sakai M, Woo J, Secombes C (2005) Characterisation and expression analysis of an interleukin 6 homologue in the Japanese pufferfish, Fugu rubripes. Dev Comp Immunol 29:775-789

67. Chen HH, Lin HT, Foung YF, Han-You Lin J (2012) The bioactivity of teleost IL-6: IL-6 protein in orange-spotted grouper (Epinephelus coioides) induces Th2 cell differentiation pathway and antibody production. Dev Comp Immunol 38:285-294

68. Wang T, Secombes CJ (2013) The cytokine networks of adaptive immunity in fish. Fish Shellfish Immunol 35:1703-1718

69. Aamelfot M, Dale OB, Weli SC, Koppang EO, Falk K (2012) Expression of the infectious salmon anemia virus receptor on atlantic salmon endothelial cells correlates with the cell tropism of the virus. J Virol 86:10571-10578

70. Wang T, Diaz-Rosales P, Costa MM, Campbell S, Snow M, Collet B, Martin SA, Secombes CJ (2011) Functional characterization of a nonmammalian IL-21: rainbow trout Oncorhynchus mykiss IL-21 upregulates the expression of the Th cell signature cytokines IFN-, IL-10, and IL-22. J Immunol 186:708-721 
71. Yuan X, Malek TR (2012) Cellular and molecular determinants for the development of natural and induced regulatory T cells. Hum Immunol 73:773-782

72. Zheng SG, Wang J, Wang P, Gray JD, Horwitz DA (2007) IL-2 is essential for TGF- to convert naive CD4+CD25-cells to CD25+ Foxp3+ regulatory T cells and for expansion of these cells. J Immunol 178:2018-2027

73. Parnes J (1989) Molecular-biology and function of CD4 and CD8. Adv Immunol 44:265-311

74. Han G, Li F, Singh TP, Wolf P, Wang XJ (2012) The pro-inflammatory role of TGFß1: a paradox? Int J Biol Sci 8:228-235

75. Zhan Y, Jimmy K (2000) Molecular isolation and characterisation of carp transforming growth factor beta 1 from activated leucocytes. Fish Shellfish Immunol 10:309-318

76. Zou J, Clark MS, Secombes CJ (2003) Characterisation, expression and promoter analysis of an interleukin 10 homologue in the puffer fish, Fugu rubripes. Immunogenetics 55:325-335

77. Inoue Y, Kamota S, Ito K, Yoshiura Y, Ototake M, Moritomo T, Nakanishi $T$ (2005) Molecular cloning and expression analysis of rainbow trout (Oncorhynchus mykiss) interleukin-10 cDNAs. Fish Shellfish Immunol 18:335-344

78. Zhang D, Shao Y-Q, Huang Y-Q, Jiang S-G (2005) Cloning, characterization and expression analysis of interleukin-10 from the zebrafish (Danio rerion). J Biochem Mol Biol 38:571-580
79. Pinto RD, Nascimento DS, Reis MIR, do Vale A, dos Santos NMS (2007) Molecular characterization, 3D modelling and expression analysis of sea bass (Dicentrarchus labrax L.) interleukin-10. Mol Immunol 44:2066-2075

80. Harun NO, Costa MM, Secombes CJ, Wang T (2011) Sequencing of a second interleukin-10 gene in rainbow trout Oncorhynchus mykiss and comparative investigation of the expression and modulation of the paralogues in vitro and in vivo. Fish Shellfish Immunol 31:107-117

81. Grayfer L, Hodgkinson JW, Hitchen SJ, Belosevic M (2011) Characterization and functional analysis of goldfish (Carassius auratus L.) interleukin-10. Mol Immunol 48:563-571

82. Wen Y, Shao JZ, Xiang LX, Fang W (2006) Cloning, characterization and expression analysis of two Tetraodon nigroviridis interleukin-16 isoform genes. Comp Biochem Physiol B Biochem Mol Biol 144:159-166

83. Wen Y, Fang W, Xiang LX, Pan RL, Shao JZ (2011) Identification of Treg-like cells in tetraodon: insight into the origin of regulatory T subsets during early vertebrate evolution. Cell Mol Life Sci 68:2615-2626

84. Reiner SL, Locksley RM (1995) The regulation of immunity to Leishmania major. Annu Rev Immunol 13:151-177

85. Dijkstra JM (2014) TH 2 and Treg candidate genes in elephant shark. Nature 511:E7-9
Ready to submit your research? Choose BMC and benefit from:

- fast, convenient online submission

- thorough peer review by experienced researchers in your field

- rapid publication on acceptance

- support for research data, including large and complex data types

- gold Open Access which fosters wider collaboration and increased citations

- maximum visibility for your research: over 100M website views per year

At BMC, research is always in progress.

Learn more biomedcentral.com/submissions 